\title{
Assimilating optical and radar data into the STICS crop model for wheat
}

\author{
Laurent PrÉvot*, Habiba Chauki, Denis Troufleau, Marie WeIsS, Frédéric BARET, Nadine Brisson \\ INRA, Unité Climat, Sol et Environnement, Domaine St-Paul, Site Agroparc, 84914 Avignon Cedex 9, France
}

(Received 27 December 2001; accepted 27 August 2002)

\begin{abstract}
The STICS crop model was recently coupled with radiative transfer (RT) models in the solar and microwave domains. This permits the simulation of the temporal variation of remotely-sensed data over wheat canopies. This paper presents the first results in assimilating remotely sensed data into STICS: comparing simulated and actual remotely-sensed data allows the recalibration of some STICS parameters so as to constrain the evolution of the simulated canopy variables. A sensitivity analysis of the coupled STICS+RT model was carried out to select the parameters of STICS with the largest influence on remotely-sensed observables and on some canopy variables (dry biomass and LAI), leading us to assess the parameters that should be recalibrated in the assimilation process, in order to adequately simulate the time course of the remotely-sensed data. In a second step, the benefits of assimilating optical data alone, radar data alone and both optical and radar data into STICS+RT were compared.
\end{abstract}

crop model / wheat / remote sensing / assimilation

Résumé - Assimilation de données de télédétection optique et radar dans le modèle STICS de culture de blé. Le modèle de culture STICS a été récemment couplé avec des modèles de transfert radiatif (RT) dans les domaines optique (du visible au moyen infrarouge) et radar. Ceci permet de simuler l'évolution temporelle de variables obtenues par télédétection au dessus d'un couvert de blé. Cet article présente les premiers résultats d'assimilation de données de télédétection dans le modèle STICS : la comparaison de données de télédétection modélisées aux données réelles permet de re-étalonner certains des paramètres de STICS, de manière à contraindre la simulation de l'évolution temporelle des variables du couvert. Une analyse de sensibilité du modèle couplé STICS+RT permet de sélectionner les paramètres de STICS ayant le plus d'effet sur les données de télédétection simulées, ainsi que sur certaines variables caractéristiques du couvert (indice foliaire et biomasse aérienne). On peut ainsi choisir les paramètres devant être ajustés dans la procédure d'assimilation, afin d'améliorer la simulation des données de télédétection. On compare ensuite les résultats obtenus en assimilant des données de télédétection optique, des données radar, et simultanément des données optiques et radar.

modèle de culture / blé / télédétection / assimilation

\section{INTRODUCTION}

Crop functioning models are useful in many agricultural and environmental applications, as they allow the prediction of the yield, but also the evolution of canopy variables such as the leaf area index or the biomass, through the crop cycle. The use of these models is, however, limited by uncertainties on the actual value of their input parameters, such as the sowing density [9] or the sowing date [13]. Recent studies have demonstrated that remotely-sensed data could improve the accuracy of crop models' predictions $[2,4,7,8,11]$. Up to now, two main approaches have been used to couple or integrate satellite data with a crop model (see [12] for a review).
(1) The inversion of radiative transfer models allows the estimation of some important canopy variables involved in the canopy functioning processes, such as the leaf area index $(L A I)$ or the fraction of absorbed photosynthetically active radiation $(F A P A R)$ in the solar domain, the surface soil moisture in the microwave domain or the evapotranspiration in the thermal infrared domain. These remotely-sensed estimates permit us to force or to recalibrate some well-identified parameters of the crop functioning model, using optimisation techniques.

(2) The crop model is coupled with an appropriate radiative transfer model, allowing the simulation of the whole 
process from canopy functioning to radiometric data. Some parameters of the coupled models are then directly recalibrated by finding the best agreement between simulated and observed remotely-sensed data. The two models are linked by one or a few common variables, such as green LAI, assuming that the other inputs of the radiative transfer model are known.

This last approach, often called assimilation, has several benefits:

- it avoids the possible inaccuracies due to the inversion scheme, since the radiative transfer model is run in direct mode;

- it allows a better use of the temporal dimension, since the crop model predictions are continuous over the cultural cycle;

- it should permit a better integration of the various spectral domains, provided that the crop functioning model includes the main processes to which the radiometric data can be related (e.g. absorption of the photosynthetically active radiation in the optical domain, soil water transfers in the microwave domain and energy balance in the thermal infrared).

This present study aims to test the improvement in the predictions of a crop model when coupled with remotely-sensed data obtained in the solar (visible and near-infrared) and radar domains. The assimilation approach was thus preferred since it allows the integration of both spectral domains in a straightforward way.

The STICS crop model [5] was recently coupled with radiative transfer models (noted as RT in what follows) in the solar and radar spectral domains [19], which permits the simulation of the temporal variation of the remotely-sensed data of wheat canopies over the crop cycle. Firstly, the models used are briefly presented and an extensive sensitivity analysis of the coupled STICS+RT model is carried out, so as to select the STICS parameters to be recalibrated in the assimilation process. We then present the first assimilation results, obtained over several wheat fields during the RESEDA experiment [15]. The benefits of assimilating optical data alone, radar data alone and both optical and radar data into STICS+RT are finally compared.

\section{MODELS USED AND SENSITIVITY ANALYSIS}

\subsection{Models used}

The crop model used in this study is the STICS model [5], developed for simulating a wide range of crops under agricultural conditions. Its main outputs comprise the above-ground production and the yield components, as well as the nitrogen and water balances of the soil-crop system, in a daily time step. In the case of wheat crops, STICS has recently been coupled with radiative transfer models in the solar (from visible to short-wave middle infrared) and in the microwave (radar) domains [19]. In the radar domain, a first-order radiative transfer code [Cloud model, 1] is used. In the optical domain, we use a multi-layer and multi-element version of the turbid model SAIL [17], coupled with the PROSPECT [10] model for the spectral properties of the leaves. These couplings allow STICS to simulate the time course of remote-sensing signatures of wheat canopies, over their crop cycle.

\subsection{Sensitivity analysis of the coupled STICS+RT model}

\subsubsection{Experimental design}

As the assimilation of remotely-sensed data into a functioning model consists of adjusting some of the parameters of the functioning model so as to minimise the difference between observed and simulated remotely-sensed data, an important preliminary step is to determine which parameters of the functioning model must be adjusted in the assimilation process. This selection of parameters is carried out through a sensitivity analysis of the coupled STICS+RT model. The selected parameters should have a large influence on the remote sensing responses, but should also affect canopy variables of interest, such as the biomass or the leaf area index. The experimental design consists of a collection of runs of the model, for various values of the input parameters. In this study, the full factorial design at three levels was chosen: for each input parameter, the standard STICS value, plus and minus $10 \%$ of its range are used to evaluate the sensitivity. For each parameter, the range is taken as the full range of variation allowed in STICS. We thus assume that taking plus and minus $10 \%$ of the range normalises the variations between parameters.

The sensitivity analysis was carried out separately, but in the same manner, for the radar and optical domains. Due to the very high number of parameters of the coupled STICS+RT model, a unique sensitivity analysis including all the STICS+RT parameters was unmanageable, since with $n$ parameters, the number of runs to perform is $3^{\mathrm{n}}$. Consequently, the sensitivity analysis was two-fold:

A first analysis was conducted separately for each of the main processes included in STICS. This per-process analysis allowed the reduction of the number of parameters to be included in the global sensitivity analysis.

In a second step, the parameters that appeared to be the most important contributors in the per-process analysis were selected for a global sensitivity analysis of the STICS+RT model.

\subsubsection{Sensitivity analysis in the radar domain}

We focused on the three radar configurations available during the ReSeDA experiment [15]: ERS (C-band, VV polarisation, $23^{\circ}$ incidence angle) and RADARSAT (C-band, HH polarisation, $23^{\circ}$ and $39^{\circ}$ incidence angles), as well as on two important canopy variables: the total above-ground dry biomass $(D M)$ and the leaf area index $(L A I)$. All variables were analysed at six key phenological stages, as defined in STICS [5]:

- LEV: emergence;

- $A M F$ : beginning of the stem elongation;

- $L A X$ : maximum of LAI;

- SEN: beginning of net senescence;

- DRP: beginning of grain filling;

- MAT: physiological maturity. 
Table I. Summary of the sensitivity of the selected output variables of interest to the parameters of STICS (iplt: sowing date; density: number of plants per $\mathrm{m}^{2}$ at emergence; extin: extinction coefficient of PAR by the canopy; $d a$ : dry bulk density of soil; $h c c l$ and $h c c 3$ : soil moisture at the field capacity for the first and third horizons; $h 1$ : initial moisture of the first horizon; $n 1$ : initial nitrogen content of the first horizon). The sensitivity increases with the number of + .

\begin{tabular}{lccccc}
\hline Parameter & DM & LAI & $\begin{array}{c}\sigma^{\circ} \\
\text { ERS }\end{array}$ & $\begin{array}{c}\sigma^{\circ}\left(23^{\circ}\right) \\
\text { Radarsat }\end{array}$ & $\begin{array}{c}\sigma^{\circ}\left(39^{\circ}\right) \\
\text { Radarsat }\end{array}$ \\
\hline iplt & +++ & +++ & + & + & + \\
density & ++ & ++ & + & + & + \\
extin & +++ & + & & & \\
da & ++ & + & ++++ & +++++ & +++++ \\
hcc1 & ++ & + & ++++ & ++++ & ++++ \\
hcc3 & ++ & + & +++ & +++ & +++ \\
h1 & ++ & + & +++ & +++ & +++ \\
n1 & ++ & + & ++ & ++ & ++ \\
\hline
\end{tabular}

The coupled STICS+RT model was run over two contrasting situations: the RESEDA wheat field 101 in 1996-97 (very dry spring, maximum LAI $=1.5$ ) and an INRA-Avignon field in 1997-98 (same cultivar, $130 \mathrm{~mm}$ more precipitation, maximum LAI = 4.8).

Table I summarises the parameters of STICS found to have the largest influence on the response of the coupled STICS+RT model in the per-process analysis. In this table, the sensitivity of the variables of interest to each STICS parameter increases with the number of + signs, related to the significance level of the sensitivity (probability associated with a Student's test). The three radar configurations were found to have similar sensitivities, that are mainly affected by the parameters describing the soil properties or driving the surface soil moisture, namely the dry bulk density $(d a)$ and the field capacity of the first horizon of soil (hccl). Among the crop parameters, only the sowing date (iplt) and the crop density (density) appear to have an important effect on the radar response of the canopy.

\subsubsection{Sensitivity analysis in the optical domain}

The same experimental design was used in the optical domain. We analysed the reflectances in three wavebands corresponding to three main distinct spectral domains: visible (red: $670 \mathrm{~nm})$, near-infrared $(850 \mathrm{~nm})$ and short-wave middle infrared $(1650 \mathrm{~nm})$. This was done for three incidence angles: $0^{\circ}, 60^{\circ}$ and hot-spot, all in the principal plane, the sun being at $45^{\circ}$ zenith angle. The analysis was carried out for the same six phenological stages as those used in the radar sensitivity analysis.

The sensitivity of the reflectance was found to be only slightly affected by the incidence angle, but large differences were found between spectral domains and phenological stages. The main results are summarised in Table II, where the number of + signs have the same signification as in Table I. The soil parameters ( $d a$ and $h c c l)$ are dominant only during
Table II. Summary of the sensitivity of the reflectance in the red $(R E D)$, near-infrared $(N I R)$ and short-wave middle infrared $(M I R)$ to the parameters of STICS: adens: compensation between stem number and plant density (dimensionless); stlevamf: duration (degree-days) of the period between the $L E V$ stage (emergence) and the $A M F$ stage (beginning of the stem elongation); other parameters: see Table I. The sensitivity increases with the number of + .

\begin{tabular}{lccccccc}
\hline Parameter & Wave band & LEV & AMF & LAX & SEN & DRP & MAT \\
\hline adens & RED & - & +++ & + & + & + & - \\
& NIR & - & ++ & ++++ & ++++ & ++++ & - \\
& MIR & - & + & ++++ & ++++ & ++++ & - \\
\hline \multirow{2}{*}{ stlevamf } & RED & - & + & - & - & - & - \\
& NIR & - & + & + & - & + & - \\
& MIR & - & + & + & + & + & - \\
\hline iplt & RED & - & ++ & - & - & - & ++ \\
& NIR & - & + & + & - & - & ++ \\
& MIR & - & + & - & - & - & ++ \\
\hline da & RED & +++ & - & - & - & - & + \\
& NIR & +++ & - & - & - & - & + \\
& MIR & +++ & - & - & - & - & + \\
\hline hcc1 & RED & +++ & - & - & - & - & + \\
& NIR & +++ & - & - & - & - & + \\
& MIR & +++ & - & - & - & - & + \\
\hline
\end{tabular}

early stages and at the end of the crop cycle, when the fraction of soil covered by the canopy is low. For intermediate growth stages, the dominant parameter is adens, a parameter of compensation between the plant density and the number of stems, which represents the ability of a plant to endure increasing densities and thus strongly influences the dynamics of the leaf area index. Visible is the most sensitive at low LAI values ( $A M F$ stage), whereas near- and middle infrared are more sensitive for higher LAI values ( $L A X, S E N$ and $D R P$ stages). This was expected, since the absorption of light by the vegetation is higher in the visible than in the near- and middle infrared, leading to a quicker saturation of remotely-sensed data with increasing LAI.

\section{ASSIMILATION OF REMOTELY-SENSED DATA}

The assimilation of remotely-sensed data into the coupled STICS+RT model was tested using the data acquired over wheat fields during the Alpilles-RESEDA experiment [15]. Assimilation was carried out using (1) optical data alone (2) radar data alone, and (3) optical and radar data together.

\subsection{Dataset}

Four wheat fields of the Alpilles-RESEDA experiment were used for assimilating remotely-sensed data: fields 101 (calibration field), 120 (irrigated field) and 300 were winter wheat crops, whereas field 214 was sowed in spring. In the optical domain, we used the airborne POLDER spectral data acquired in nadir-viewing in the green $(565 \mathrm{~nm})$, red $(670 \mathrm{~nm})$ and near-infrared $(865 \mathrm{~nm})$ channels. The POLDER instrument repeatedly covered the site with acquisitions on days 
378, 396, 424, 437, 451, 466, 472, 488, 508, 526 and 555 (as the RESEDA experiment started in October 1996 and ended in October 1997, the origin of the dates was chosen as 01/01/1996, day 367 being 01/01/1997). The POLDER data were calibrated and corrected for atmospheric effects, thus expressed as top of the canopy reflectances. In the radar domain, we used the images acquired by the synthetic aperture radars (SAR) aboard the ERS (C-band, VV, 23 ${ }^{\circ}$ ) and RADARSAT $\left(\mathrm{C}\right.$-band, $\left.\mathrm{HH}, 23^{\circ}\right)$ satellites, calibrated and expressed in $\mathrm{dB}$ units. Radar data were also acquired repeatedly, with acquisitions on days 344, 389, 392, 424, 462, 494 and 529 for Ers and days 449, 472, 497 and 521 for RadarSat at $23^{\circ}$ incidence angle (the data acquired at $39^{\circ}$ incidence angle were not used in the present study).

\subsection{Assimilation procedure and parameters fitted}

The assimilation of remotely-sensed data into the coupled STICS+RT model is carried out by finding numerically [14] the parameters of STICS that minimise the weighted sum of the squared differences between simulated and observed remotely-sensed data. The weights, respectively 0.03 for the solar domain and $1.2 \mathrm{~dB}$ for the radar domain, account for the inaccuracy of the radiative transfer models and for the observed within-field variability of the remotely-sensed data. This minimisation is performed with all the data available during the crop cycle.

Five parameters of STICS were chosen as assimilation parameters:

- iplt: sowing date;

- adens: compensation between stem number and stem density;

- stlaxsen: duration of the period between the $L A X$ stage (maximum of LAI) and the SEN stage (beginning of net senescence);

- hccl: field capacity of the first horizon of soil;

- $q_{0}$ : parameter defining the end of the maximum evaporation stage of the soil.

Two of these parameters, stlaxsen and $q_{0}$, were not selected in the sensitivity analysis, but were added after examining the results of the first assimilation attempts: without including these parameters, the temporal evolution of the LAI at the end of the crop cycle (influenced by stlaxsen) and the decrease in the surface soil moisture during dry periods (influenced by $q_{0}$ ) were always incorrectly reproduced, even after assimilation. This is likely to be due to a drawback of our two-step sensitivity analysis: these parameters were not kept after the per-process analysis and thus were not included in the global sensitivity analysis.

One can notice that the five parameters are of varying status: iplt corresponds to agricultural practices, adens and stlaxsen are cultivar-dependant, whereas $q_{0}$ and $h c c l$ are related to the properties of the soil top layer.

The other parameters of STICS were kept constant, most of them at their standard values given in STICS and some of them (namely, those describing the soil properties) at values resulting from field measurements or from a preliminary calibration of STICS against the ground data acquired on the field 101 of the RESEDA experiment.
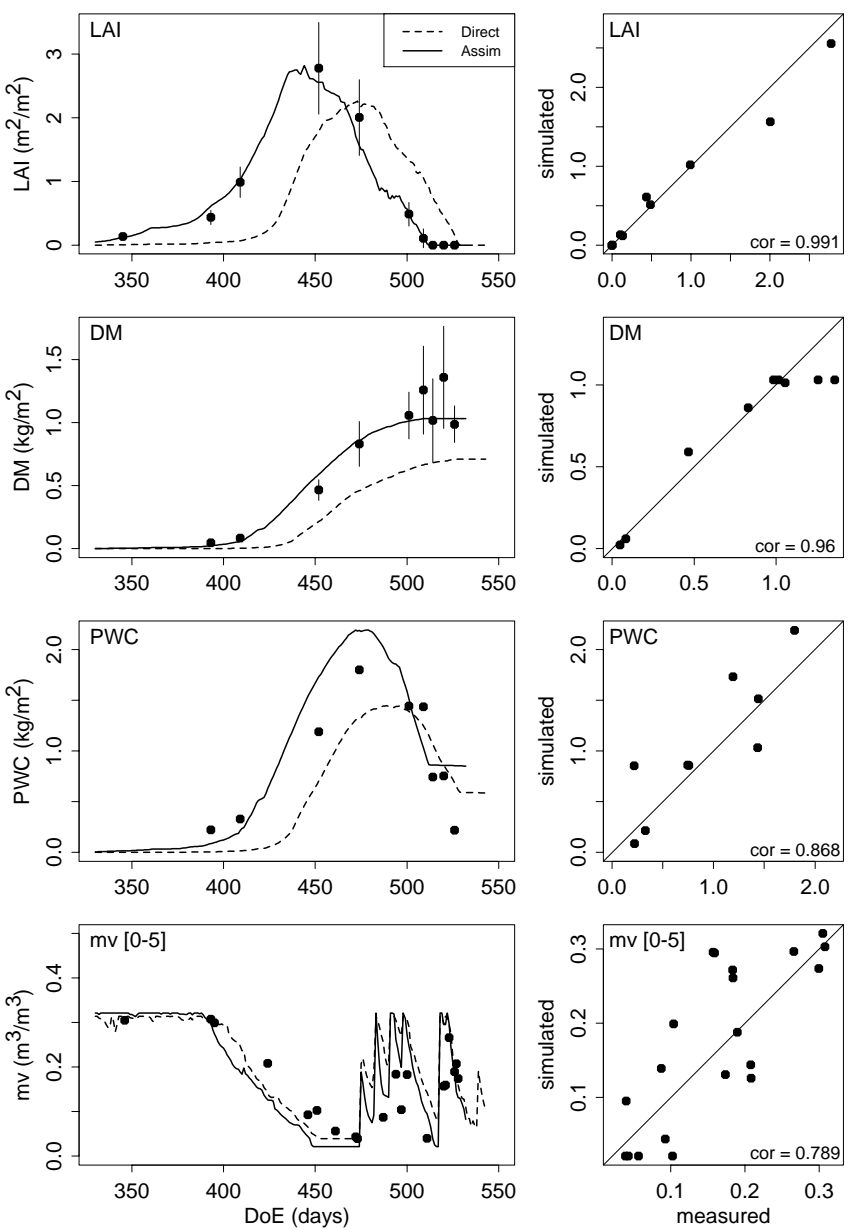

Figure 1. Results of STICS simulations on RESEDA wheat field 300, when assimilating POLDER data, for the four selected variables of interest ( $L A I, D M, P W C$ and $m v$ ). Graphs in the left column give the temporal evolution of these variables (solid line: STICS with assimilation of remotely-sensed data; broken line: STICS in direct mode i.e. without assimilation; solid circles: measured values; with error bars); the time is expressed in days (DOE=367 is $01 / 01 / 1997$ ). Graphs in the right column present the simulated vs. measured values (the solid line is the 1:1 line); cor is the correlation coefficient between measured and assimilated values; rms values are given in Table III.

\subsection{Assimilation results}

The effect of assimilating remotely-sensed data into STICS was tested by comparing the evolution of some selected output variables when running STICS without assimilation (hereafter called direct mode) and when assimilating optical (POLDER) and/or radar (SAR) data. Four output variables were chosen for their interest and their influence on the radiometric signatures: the leaf area index $L A I\left(\mathrm{~m}^{2} / \mathrm{m}^{2}\right)$, the total above-ground dry matter $D M\left(\mathrm{~kg} / \mathrm{m}^{2}\right)$, the total plant water content $P W C\left(\mathrm{~kg} / \mathrm{m}^{2}\right)$ and the surface soil moisture in the $0-5 \mathrm{~cm}$ layer $m v$ (in volumetric units, $\mathrm{m}^{3} / \mathrm{m}^{3}$ ).

Figure 1 presents the temporal evolution of the four selected output variables, without assimilation and when assimilating POLDER data, for RESEDA wheat field 300. 

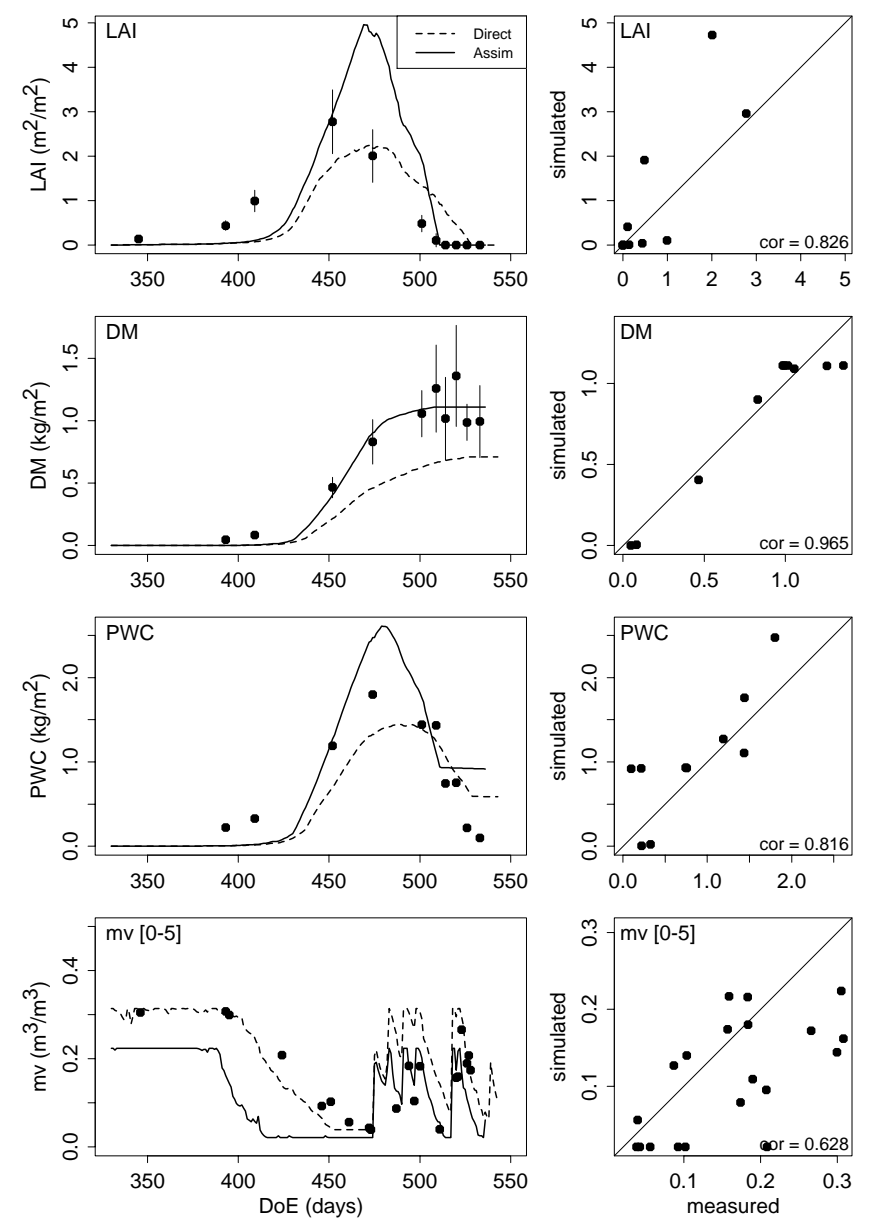

Figure 2. Results of STICS simulations on RESEDA wheat field 300 when assimilating radar data, for the four selected variables of interest (LAI, DM, PWC and $m v$ ). Same legend as Figure 1.

Thanks to the rather large number of POLDER images available during the wheat crop cycle (11 acquisition dates) a clear improvement is observed on the vegetation variables ( $L A I$, $D M$ and, to a lesser extent, $P W C$ ) when assimilating optical data. We note that the shape of the temporal evolution of LAI is greatly improved: the development of LAI is faster at early stages, and the maximum of LAI is reached about one month sooner, as well as the senescence. Adversely, the assimilation of optical data does not improve the prediction of the surface soil moisture $m v$.

Figure 2 presents the same results as Figure 1, when assimilating SAR data. The simulated evolution of the leaf area index $(L A I)$ and of the plant water content $(P W C)$ is clearly worse, compared with the direct mode. This can be related to the low sensitivity of the radar data to the vegetation, at least in the C-band. Simulated values of the surface soil moisture $m v$ appear to be slightly improved when looking at the root mean square errors (hereafter noted as rms and given in Tab. III) but are clearly underestimated during the saturation phase, at the beginning of the cycle (before day 400). Improving the modelling of the surface soil moisture in STICS is thus
Table III. Summary of the results of assimilating optical data alone $(P O L D E R)$, radar data alone (SAR) or optical and radar data $(P O L D E R+S A R)$ in STICS, compared with the Direct mode (STICS running without assimilation of remotely sensed data), for four of the RESEDA wheat fields. Results are expressed as the root mean square error $(r m s)$ of the simulated values, for the four selected variables (LAI, DM, PWC and $m v)$. The results are given for each field (101, 120, 300 and 214) and all together (All).

\begin{tabular}{|c|c|c|c|c|c|}
\hline Field & Mode & LAI & PWC & DM & $\mathrm{mv}$ \\
\hline 101 & Direct & 0.57 & 0.36 & 0.12 & 0.068 \\
\hline \multirow[t]{3}{*}{ (calibration field) } & POLDER & 0.55 & 0.46 & 0.16 & 0.055 \\
\hline & SAR & 0.88 & 0.64 & 0.17 & 0.059 \\
\hline & $\begin{array}{c}\text { POLDER } \\
\text { +SAR }\end{array}$ & 0.46 & 0.36 & 0.13 & 0.062 \\
\hline 120 & Direct & 1.16 & 0.52 & 0.12 & 0.105 \\
\hline \multirow[t]{3}{*}{ (irrigated field) } & POLDER & 0.57 & 0.30 & 0.13 & 0.110 \\
\hline & SAR & 1.07 & 0.53 & 0.13 & 0.107 \\
\hline & $\begin{array}{c}\text { POLDER } \\
+ \text { SAR }\end{array}$ & 0.56 & 0.30 & 0.12 & 0.101 \\
\hline \multirow[t]{4}{*}{300} & Direct & 0.63 & 0.39 & 0.19 & 0.079 \\
\hline & POLDER & 0.17 & 0.34 & 0.14 & 0.068 \\
\hline & SAR & 0.98 & 0.42 & 0.12 & 0.072 \\
\hline & $\begin{array}{c}\text { POLDER } \\
+ \text { SAR }\end{array}$ & 0.16 & 0.35 & 0.16 & 0.058 \\
\hline 214 & Direct & 0.46 & 0.16 & 0.07 & 0.065 \\
\hline \multirow[t]{3}{*}{ (spring wheat) } & POLDER & 0.28 & 0.33 & 0.13 & 0.054 \\
\hline & SAR & 0.63 & 0.31 & 0.11 & 0.058 \\
\hline & $\begin{array}{c}\text { POLDER } \\
+ \text { SAR }\end{array}$ & 0.63 & 0.31 & 0.11 & 0.058 \\
\hline \multirow[t]{4}{*}{ All } & Direct & 0.74 & 0.38 & 0.17 & 0.087 \\
\hline & POLDER & 0.46 & 0.37 & 0.14 & 0.085 \\
\hline & SAR & 0.88 & 0.52 & 0.16 & 0.084 \\
\hline & $\begin{array}{c}\text { POLDER } \\
\text { +SAR }\end{array}$ & 0.61 & 0.35 & 0.18 & 0.082 \\
\hline
\end{tabular}

clearly necessary for a better assimilation of radar data into STICS. However, one must keep in mind that the root mean square error $(r m s)$ on surface soil moisture obtained after assimilation $\left(\approx 0.08 \mathrm{~m}^{3} / \mathrm{m}^{3}\right)$ is of the same order of magnitude as the rms on the estimation of the surface soil moisture by inversion of the CLOUD model [16].

Figure 3 presents the same results as Figure 1, when assimilating POLDER and Sar data together. Compared with the assimilation of POLDER data alone (see Fig. 1), adding radar data appears to improve only slightly the $L A I$ prediction. Plant water content $P W C$ simulation is also slightly improved in the 

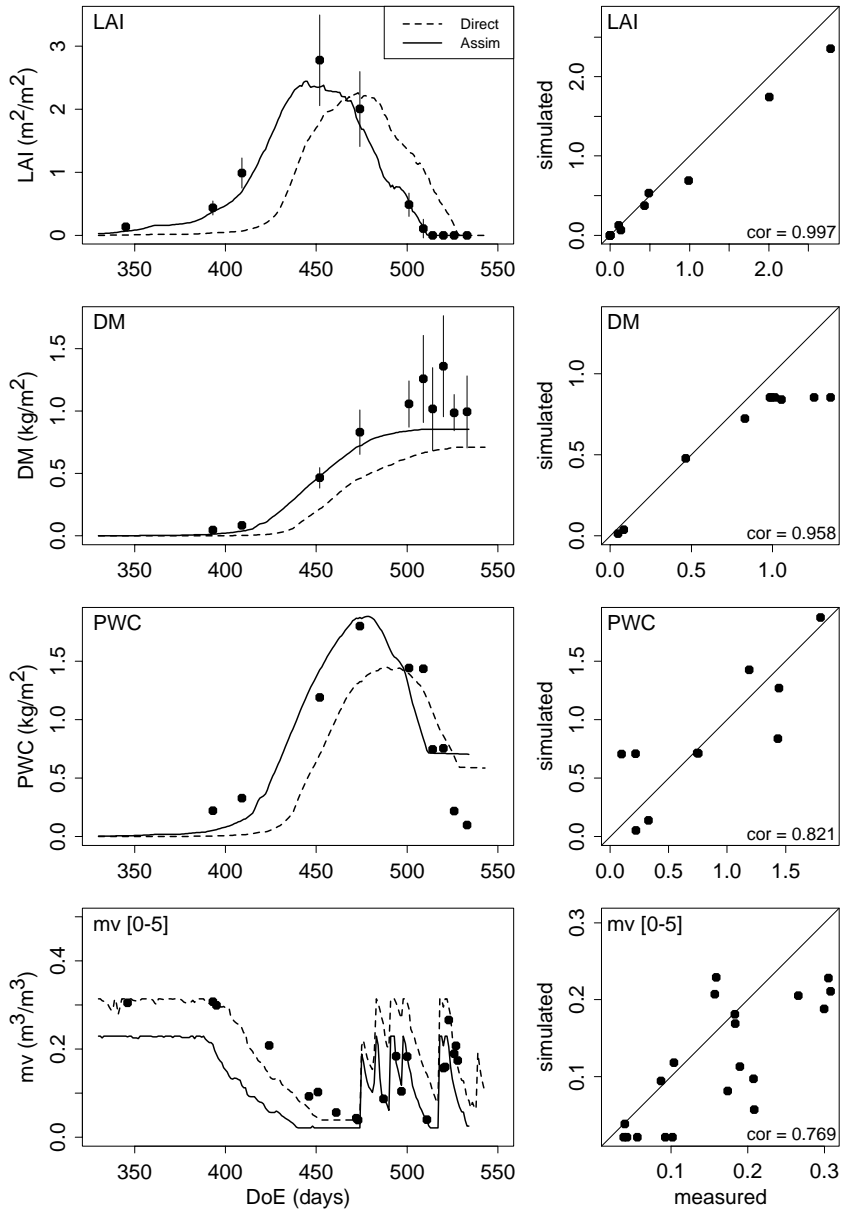

Figure 3. Results of STICS simulations on RESEDA wheat field 300 when assimilating simultaneously POLDER and radar data, for the four selected variables of interest (LAI, DM, PWC and $m v$ ). Same legend as Figure 1.

middle of the crop cycle (at its maximum values) but is globally worsened, as is the dry matter $D M$ prediction. Simulation of the surface moisture $m v$ is slightly improved, and is even better than in Figure 2 (radar data alone), with the same discrepancy at the beginning of the crop cycle.

The results of assimilation for the four RESEDA wheat fields are given in Table III and can be summarised as follows. A clear improvement in the prediction of the vegetation variables (namely, $L A I$ and $D M$ ) is observed when assimilating POLDER data, for fields 120 and 300. The improvement is less pronounced for fields 101 and 214, but one must keep in mind that on the one hand, field 101 was used for calibrating some of the parameters of STICS, and that on the other hand, field 214 was sown in spring and exhibited an extremely low development of the canopy (maximum LAI $=1.1$ ), due to an abnormally dry spring (no rain between the end of January and beginning of April, days 388 to 475). The residual error on LAI estimates when assimilating POLDER data (see line All/ POLDER in Tab. III) is 0.46 , which is close to the accuracy of LAI estimates in the REDEDA dataset through a neural network trained on the SAIL model: $r m s=0.49$ [18].
The results obtained when assimilating radar data alone are generally worse than those given by the direct mode, except for a slight improvement for the surface soil moisture. The low sensitivity of the radar signal to the vegetation parameters and the difficulty in simulating correctly the surface soil moisture when close to saturation (at the beginning of the cycle) are likely to have a strong effect on the assimilation of radar data. The number of radar images is also probably too low, since because of the quick variations of the surface soil moisture, a 3- to 9-day repeat cycle would be required for a good monitoring of surface soil moisture and a proper estimation of soil water content from microwave remotely-sensed data $[3,6]$.

When compared with the assimilation of optical data alone, the simultaneous assimilation of optical and radar data does not permit a clear amelioration, which might be due to the difficulties in simulating the evolution of surface soil moisture, but could also be related to the large improvement already obtained with the optical data alone. Only a slight improvement in the predicted plant water content and surface soil moisture is observed.

\section{CONCLUDING REMARKS}

Coupling the STICS crop model with radiative transfer models in the optical (solar) and radar domains allowed the testing of the assimilation of remotely-sensed data in STICS. The introduction of optical data leads to a clear improvement in the accuracy of leaf area index and above-ground dry matter predicted by STICS over the crop cycle, thanks to the large number of available optical data.

The assimilation of radar data does not permit the improvement of the predictions and further improvements in the simulation of the surface soil moisture are obviously needed for a better integration of radar data into STICS. Also, the amount of available radar data might not be large enough for that purpose.

This study also demonstrates that assimilating simultaneously remotely-sensed data from various sensors (optical and radar) into a crop model is feasible, even if, as in our case, the introduction of the radar data did not improve the accuracy of the simulated values. Such simultaneous assimilation could be of great interest when the cloud cover limits the number of available optical images.

Acknowledgements: This study was carried out within the framework of the Alpilles-RESEDA project, funded by the EEC-DG XII and by the French Programme National de Télédétection Spatiale and Programme National de Recherches en Hydrologie; ESA-ESRIN provided the ERS images.

\section{REFERENCES}

[1] Attema E.P.W., Ulaby F.T., Vegetation modeled as a water cloud, Radio Sci. 13 (1978) 357-364.

[2] Bach H., Yield estimation of corn based on multitemporal LANDSAT-TM data as input for an agrometeorological model, Pure Appl. Opt.: J. Eur. Opt. Soc. Part A 7 (1998) 809-825.

[3] Bernard R., Vauclin M., Vidal-Madjar D., Possible use of active microwave remote sensing data for prediction of regional evaporation by numerical simulation of soil water movement in the unsaturated zone, Water Resour. Res. 17 (1981) 1603-1610. 
[4] Bouman B.A.M., Crop modelling and remote sensing for yield prediction, Ned. J. Agric. Sci. 43 (1995) 143-161.

[5] Brisson N., Mary B., Ripoche D., Jeuffroy M.H., Ruget F., Nicoullaud B., Gate P., Devienne-Barret F., Antonioletti R., Durr C., Richard G., Beaudoin N., Recous S., Tayot X., Plenet D., Cellier P., Machet J.M., Meynard J.M., Delécolle R., STICS: a generic model for the simulation of crops and their water and nitrogen balances. I. Theory and parameterization applied to wheat corn, Agronomie 18 (1998) 311-346.

[6] Calvet J.C., Noilhan J., From near-surface to root-zone soil moisture using year-round data, J. Hydrometeorol. 1 (2000) 393-411.

[7] Choudhury B., Global pattern of potential evaporation calculated from the Penman-Monteith equation using satellite and assimilated data, Remote Sens. Environ. 61 (1997) 64-81.

[8] Fischer A., Kergoat L., Dedieu G., Coupling satellite data with vegetation functional model: review of different approaches and perspectives suggested by the assimilation strategy, Remote Sens. Rev. 15 (1997) 283-303.

[9] Guérif M., Duke C., Calibration of the SUCROS emergence and early growth module for sugar beet using optical remote sensing data assimilation, Eur. J. Agron. 9 (1998) 127-136.

[10] Jacquemoud S., Baret F., PROSPECT: a model of leaf optical properties spectra, Remote Sens. Environ. 34 (1990) 75-91.

[11] Maas S., Using satellite data to improve model estimates of crop yield, Agron. J. 80 (1988) 655-662.

[12] Moulin S., Bondeau A., Delécolle R., Combining agricultural crop models and satellite observations: from field to regional scales, Int. J. Remote Sens. 19 (1998) 1021-1036.

[13] Moulin S., Dedieu G., Fischer A., Assimilation of optical satellite data into a crop process model: interannual study, in: Guyot G., Phulpin T. (Eds.), 7th International Symposium on Physical Measurements and Signatures in Remote Sensing, Courchevel, France, 1997, pp. 767-771.
[14] Nelder J.A., Mead R., A simplex method for function minimization, Comput. J. 7 (1965) 308-313.

[15] Prévot L., Baret F., Chanzy A., Autret H., Baudin F., Bessemoulin P., Bethenod O., Blamont D., Blavoux B., Bonnefond J.M. Boubkraoui S., Bouman B.A.M., Braud I., Bruguier N., Calvet J.C., Caselles V., Chauki H., Clevers J.G.P.W., Coll C., Company A., Courault D., Dedieu G., Degenne P., Delécolle R., Denis H., Desprats J.F., Ducros Y., Dyer D., Fies J.C., Fischer A., François C., Gaudu J.C., Gonzalez-Soza E., Goujet R., Gu X.F., Guérif M., Hanocq J.F., Hautecoeur O., Haverkamp R., Hobbs S., Jacob F., Jeansoulin R., Jongschaap R.E.E., Kerr Y., King C., Laborie P., Lagouarde J.P., Laques A.E., Larcena D., Laurent G., Laurent J.P., Leroy M., McAneney J., Macelloni G., Moulin S., Noilhan J., Ottlé C., Paloscia S., Pampaloni P., Podvin T., Quaracino F., Roujean J.L., Rozier C., Ruisi R., Susini C., Taconet O., Tallet N., Thony J.L., Travi Y., Leewen H.v., Vauclin M., Vidal-Madjar D., Vonder O.W., Weiss M., Assimilation of Multi-Sensor and MultiTemporal Remote Sensing Data to Monitor Vegetation and Soil: the Alpilles-RESEDA project, in: Stein T. (Ed.), IGARSS'98, International Geoscience and Remote Sensing Symposium, Managing the Environment, Seattle, USA, 1998, pp. 2399-2401.

[16] Prévot L., Champion I., Guyot G., Estimating surface soil moisture and leaf area index of a wheat canopy using a dual-frequency $(\mathrm{C}$ and X bands) scatterometer, Remote Sens. Environ. 46 (1993) 331-339.

[17] Verhoef W., Light scattering by leaf layers with application to canopy reflectance modeling: the SAIL model, Remote Sens. Environ. 16 (1984) 125-141.

[18] Weiss M., Baret F., Leroy M., Hautecoeur O., Bacour C., Prévot L., Bruguier N., Validation of neural net techniques to estimate canopy biophysical variables from remote sensing data, Agronomie 22 (2002) 547-553.

[19] Weiss M., Troufleau D., Baret F., Chauki H., Prévot L., Olioso A., Bruguier N., Brisson N., Coupling canopy functioning and canopy radiative transfer models for remote sensing data assimilation. The case of winter wheat, Agric. For. Meteorol. 108 (2001) 113-128. 